Session 3247

\title{
Integrated Tool Design and Manufacturing within Advanced Hands-on Projects
}

\author{
Ismail Fidan $^{1}$, Ali Sekmen ${ }^{2}$, Fred Vondra ${ }^{1}$ \\ ${ }^{1}$ Tennessee Tech University, Cookeville, TN 38505/ ${ }^{2}$ Tennessee State University, \\ Nashville, TN 37209
}

\begin{abstract}
In most manufacturing technology programs, CAD, CNC, CAM, and Manufacturing Processes courses are usually the main components of any NAIT or TAC-ABET accredited curriculum. Currently these courses are offered in separate sequential semesters and students have no opportunity to practice their separate learnings within a step-by-step, integrated, hands-on project environment. In this paper, authors will present their implementation practiced at the Tennessee Tech University. Tooling projects are decided between the faculty members and students first, and then the following steps are followed:
\end{abstract}

- Set up the project objectives and student gaining first.

- Select a project topic and investigate the alternative production methods, resources available and make a lifecycle and cycle time analysis.

- Distribute the work in team and schedule the activities.

- Design the part and required tooling using available CAD packages: 2D(AutoCAD), 3D(Mechanical Desktop and Pro/Engineer).

- Generate the CNC machining code: molds or parts are virtually machined and simulated using CNCez or MasterCAM. 
- Select or build the tooling and fixtures.

- Machine, cast, or form the part.

- Post process the part for extra trimming, polishing, and painting.

- Present, discuss, and report the lifecycle analysis, problems faced, and troubleshooting. Since Internet is rapidly being adopted in technology education as a tool for enhancing the educational experience of students residing on campus as well as to expand the reach of unique programs beyond the local campus, this new design and manufacturing course has also been practiced and implemented via Internet tools; i.e. WebCT, Webmail, Web Companions, and Online tools (i.e.: material selection, tool selection, process parameters selection, and cutting data). This paper reports the milestones, assessment, and web-based control in these projects and newly developed course.

\section{Introduction}

Incorporating many manufacturing principles to achieve a final part involves many steps and time constraints. Usually students are expected to have such a practice during their graduation thesis. Currently, there is no graduation thesis possibility in MIT curriculum ${ }^{1-3}$. MIT 4500, Tool Design course makes students' learning more solid and hands-on since it involves most of the students' past learnings.

The fundamental tooling concepts are lectured during the lecture hours ${ }^{4-5}$. All student projects are accomplished in the lab hours. First the projects are proposed by the teams and finalized by the instructors. There is a pre-defined structure followed by the students for each project. The followings are the main steps followed by teams formed:

- Design the project part and its components on any CAD package.

- Write a CNC program to cut out a part or pattern.

- Simulate the alternative paths, methods and cycle time.

- Finalize the process tooling, workpiece material, and cutting tool.

- Post process the part: trimming, deburring, grinding, and polishing etc.

- Cast the part out of aluminum or bronze if needed.

- Finish the surfaces with manual machining operations and hand finishing. 
- Estimate the cycle time and lifecycle, and come up with some alternative solutions to lower the values of estimated cost and time for mass production.

- Report the development, problems faced, trouble-shootings, and team participation.

\section{Start Phase}

A number of different industrial project ideas is collected and discussed by the instructors. Due to the resources, external funding, time constraints, and customer requirements, projects are short-listed and teams are formed. Frequent discussions and exchanges of ideas are accomplished between the teams and instructors. In order to clearly present this integrated design and manufacturing method, the project steps are explained with a sample project part, which is a wagon wheel.

\section{CAD Phase}

Computer-Aided Design tools; e.g. AutoCAD, Mechanical Desktop, or Pro/Engineer are used to design the details of the projects. These drawings are used to obtain the dimensions of the machined part and create a solid model of the cast part. Surface finish properties, tolerances, assembly components, manufacturing process properties, sectional details, and materials used are all detailed in this phase. Each revision is recorded and new changes are directly added under a new revision file. Figure 1 presents a detailed drawing created for the manufacturing of a wheel assembly component. 

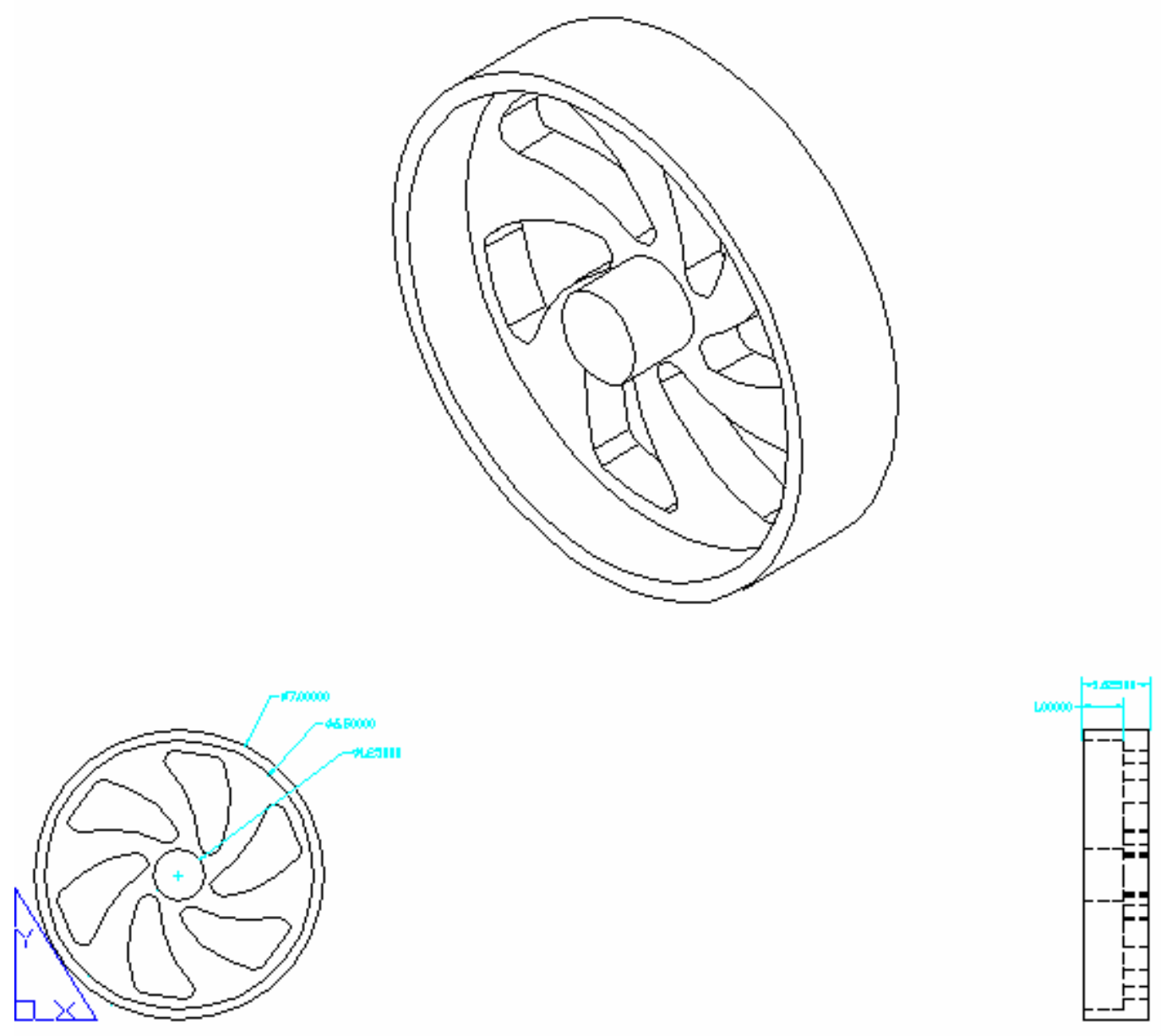

Figure 1: Detailed 2D and 3D design of wagon wheel

\section{CNC Machining Simulation Phase}

Once the project design details are completed and vital coordinates are retrieved, teams are able to write the code for the machined parts with $\mathrm{G}$ and M commands. Some particular designs are basically composed of complicated G codes, but usually G00 (rapid tool positioning), G01 (linear feed cut into the part), G02/G03 (arc-feed cuts) and G83 (drilling cycles) are used. CNC simulators; $\mathrm{CNCez}^{6}$ and $\mathrm{MasterCAM}^{7}$ are used to demonstrate the dynamics of the program code. Some of the main requirements in team projects were to come up with a lower cycle time and add draft angles and corner/fillet radiuses. Figure 2 shows some snapshots from the CAM simulation stages. 

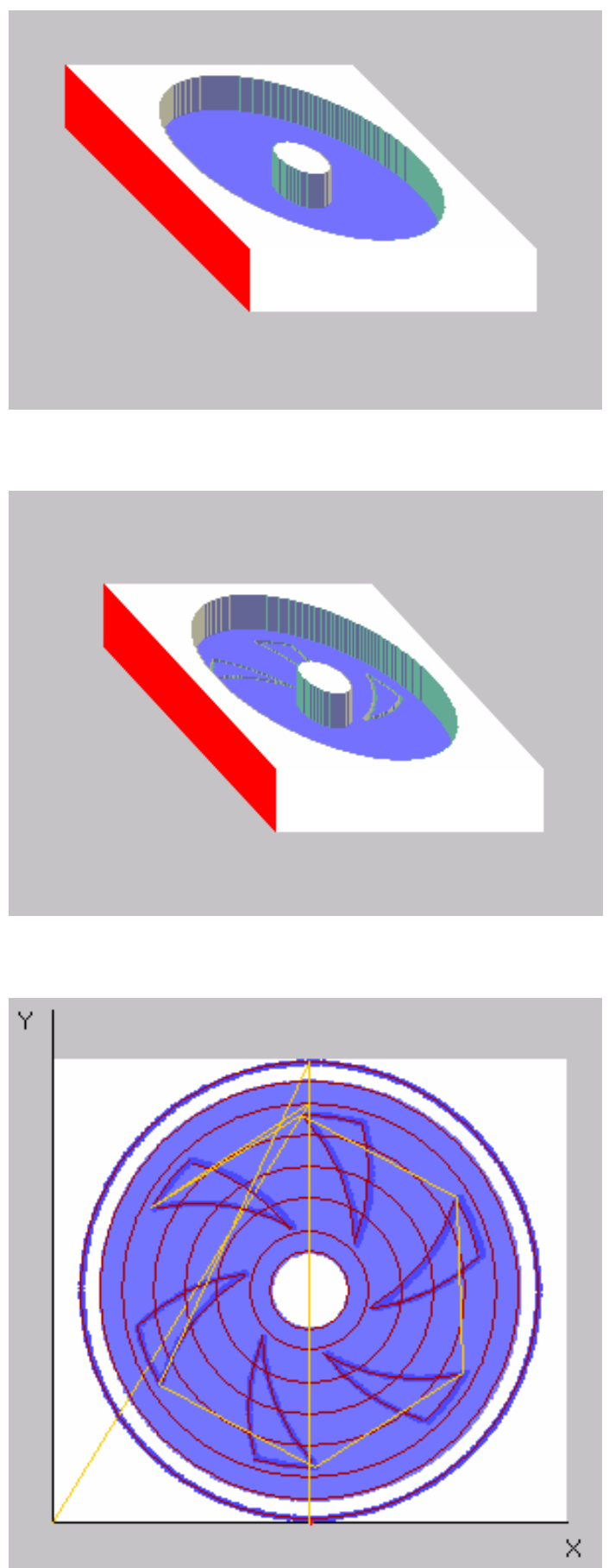

Figure 2: Snapshots from the wagon wheel CAM stages

Wheel cut with 51 arcs, G02/G03 codes made up approximately 75\% of code 


\section{Machining Phase}

After the programs are developed and debugged via CNCez or MasterCAM, codes are taken to the CNC lab. All tooling is set up, and the Fadal Machining Center is turned on. PRZs (coordinate zeros) are set up and the tool offsets are computed. After the program was uploaded, the Fadal machine is ready for action. Finally, after some time of machining, chunk of poplar is turned into a rough model of any project part. Figure 3 shows some sample stages from wagon wheel machining.
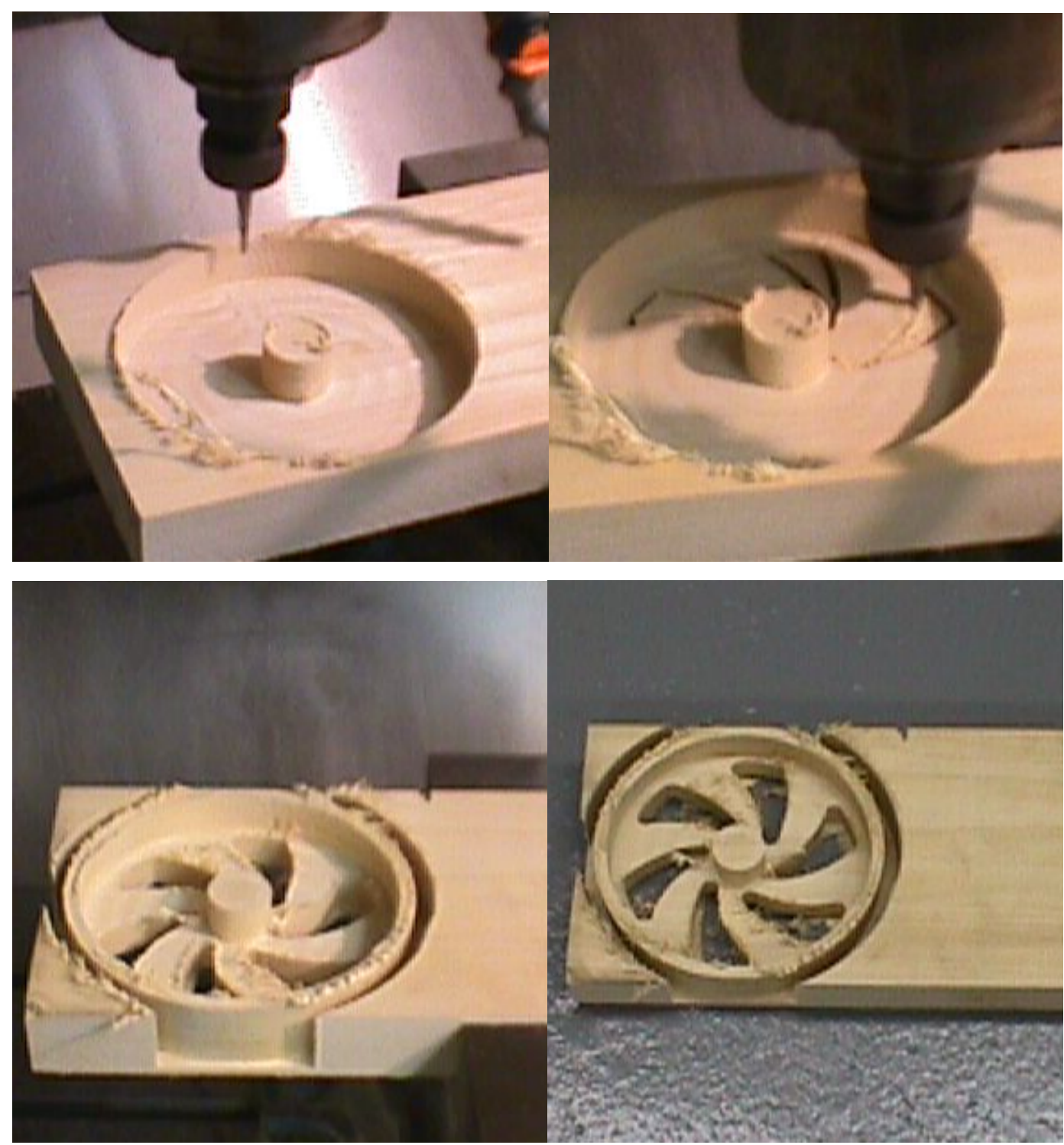

Figure 3: Machined patterns of a wagon wheel 


\section{Post Machining Phase}

After the part is removed from the vice of the Fadal machining center, the part is cut from its original rough material. Then, it is roughly finished with 100-grit sandpaper to knock off splinters and prepare the surface for further finishing due to the design requirements. Wood putty is used to create a fillet around the center and the outside rim of the wheel. 600-grit sandpaper shapes the fillets and, also, further smoothes the surface.

Polyurethane coats the outside of the wheel to seal and protect it. Figure 4 shows the post machined parts.
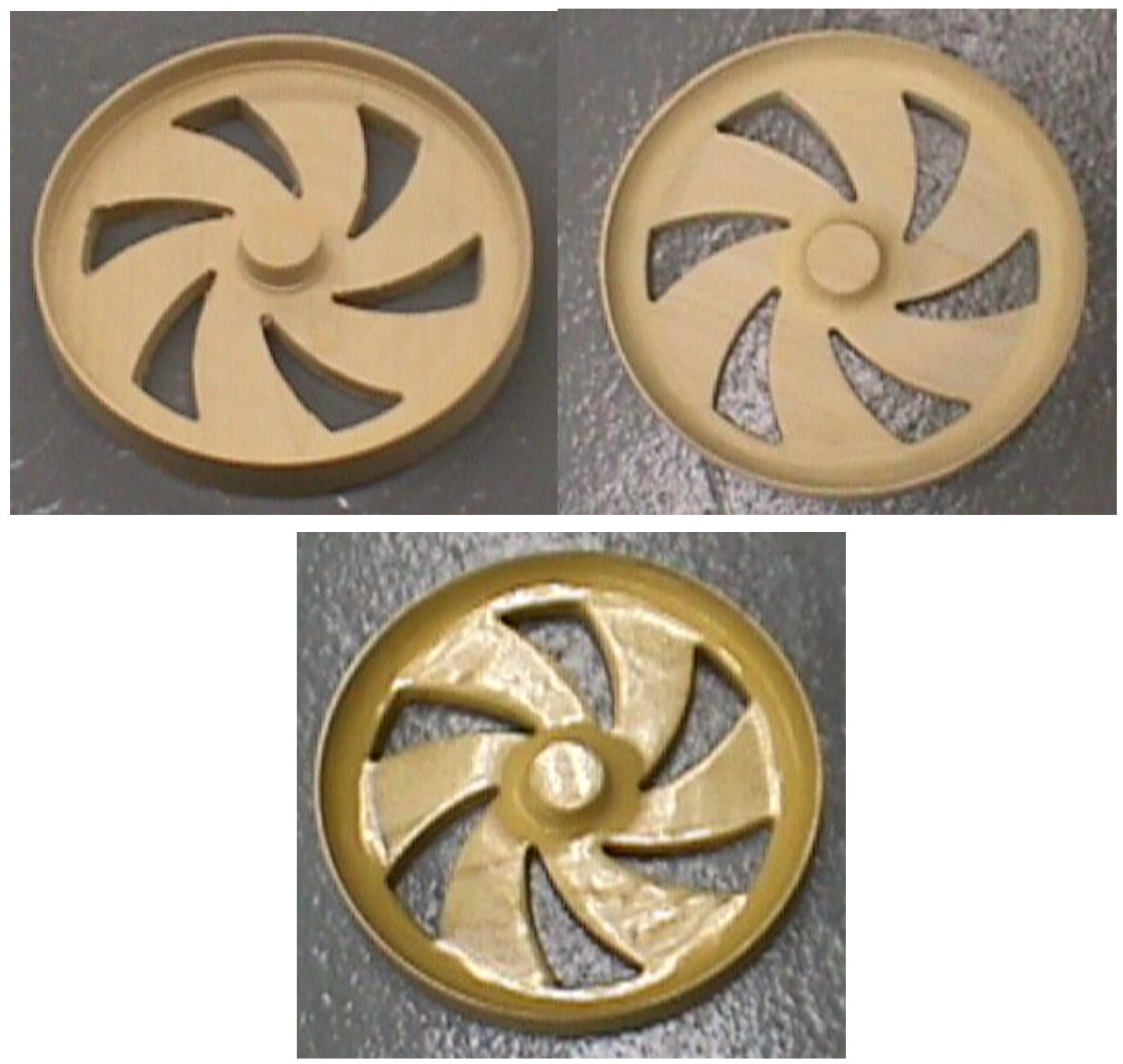

Figure 4: Post machined wagon wheel samples 


\section{Casting Phase}

The pattern is finished and ready to cast. Team members hand-ramm petrabond sand around the pattern to make a mold. After the gating system is carved out of the sand, the mold is ready to be poured. Aluminum at $1400^{\circ} \mathrm{F}$ is forced into the mold cavity creating the parts given below in Figure 5.
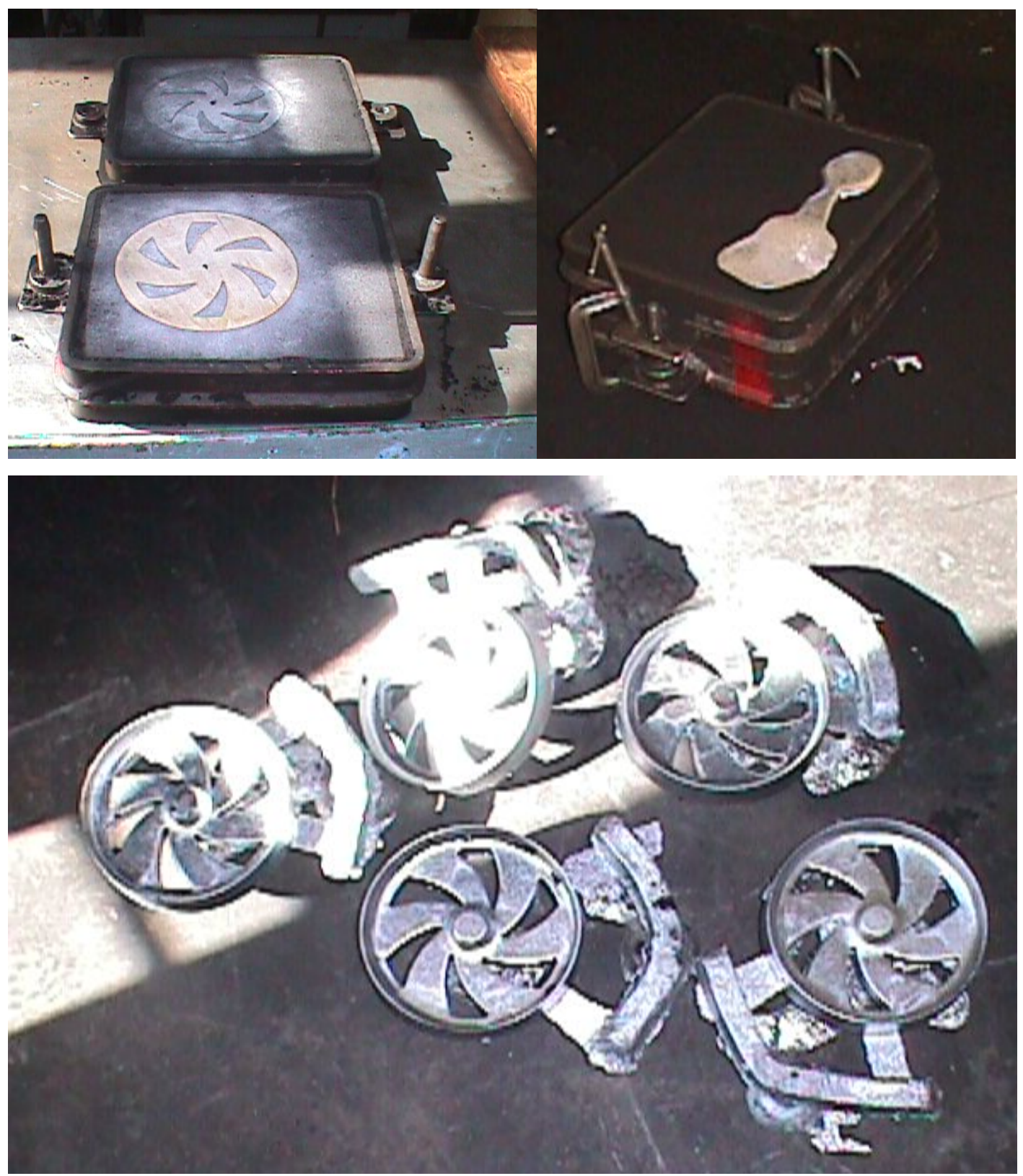

Figure 5: Views from the casting stage 


\section{Post Processing Phase}

Finally, it is time to finish the project parts and reveal the final product. First, the gating systems are cut off and filed down to protect the machining tools. Then, each wheel is placed on a manual-milling machine to flatten the top and bottom faces. Also, the hole is marked and drilled in the center while at the milling machine. Next, the wheel is mounted on the faceplate of a manual lathe to achieve trueness around the diameter of the wheel. Also, the back of the wheel is faced to achieve a certain finished look. The last step of the finishing process is a lengthy one. It involves sanding the face of the wheel with 100-grit, 220-grit, 380-grit, 440-grit, 600-grit, 800-grit, and 1000-grit sandpaper. Then, metal polish is used to shine and brighten the ending result. Figure 6 shows a postprocessed part. Figure 7 presents some finished wagon wheels.
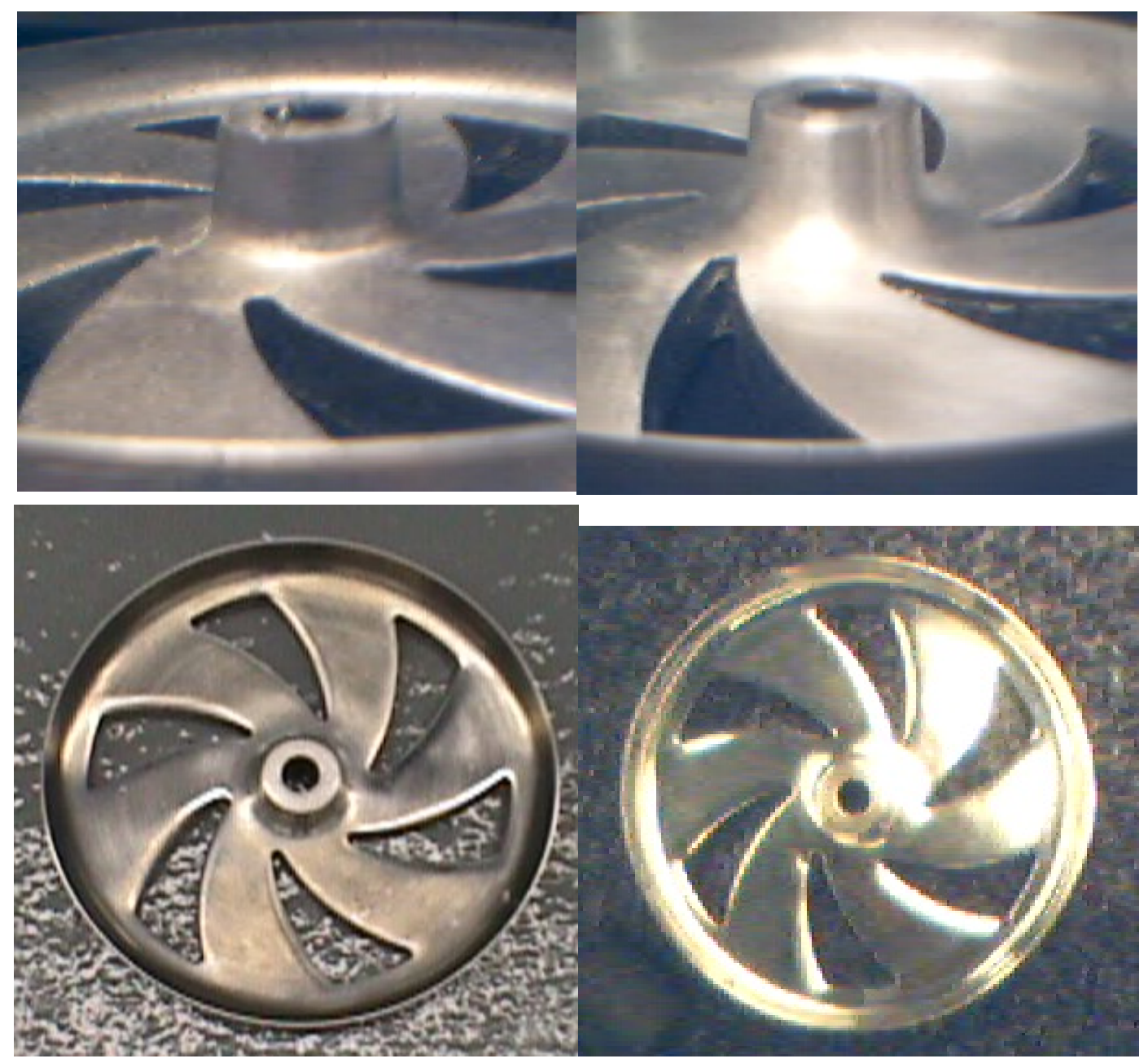

Figure 6: Post processed project parts 


\section{Analytical Studies Phase}

These tool design projects reveal many hidden aspects of manufacturing processes such as design, machining, tooling, and casting. The followings are some samples from the wagon wheel project.

1. Trial and Error Runs, Troubleshooting Practices: After team's first wooden pattern was completed, students forgot to add a draft angle. The casting process demanded this characteristic in order to preserve the mold when the pattern was removed. So, students had to reproduce the part using different tools than the previous time. They used a $1 / 8^{\prime \prime}$ bit with a $5^{\circ}$ taper on all of these vertical edges.

2. Detailed understandings on Manufacturing Processes: The fillets used around the inside corners of the wheel face were much easier to incorporate in the design of the wheel. This characteristic provided multiple bonuses to the design integrity. It gave a smooth rounded surface that allowed for easier finishing of the product and, also, preserved the mold when the pattern was removed from the sand.

3. Effects of Shrinkage and Chip Removal: Every time that something is done to improve the surface of a product, material has to be removed. The end result of all of the finishing of a part may be significantly smaller than the original design. Therefore, the effects of chip removal and shrinkage should be carefully added to teams' CAD design phase initially.

4. Cycle Time and Life Cycle Analysis: Entire process from row-stuck material to final finished part and from design stage to usable finished part is analyzed in terms of cost of each stage, time spent, alternative production methods, troubleshooting and future developments, as can be seen in Figure 8. Since the cost and time are the two important factors in any manufacturing process, any possible way to lower down both factors are considered deeply. Alternative cutting tools, layout changes, and different materials are tried to accomplish these objectives. The common problems we faced were the tool breakdowns, 
use of tougher materials and lower feed rates, which cause very long cycle times.

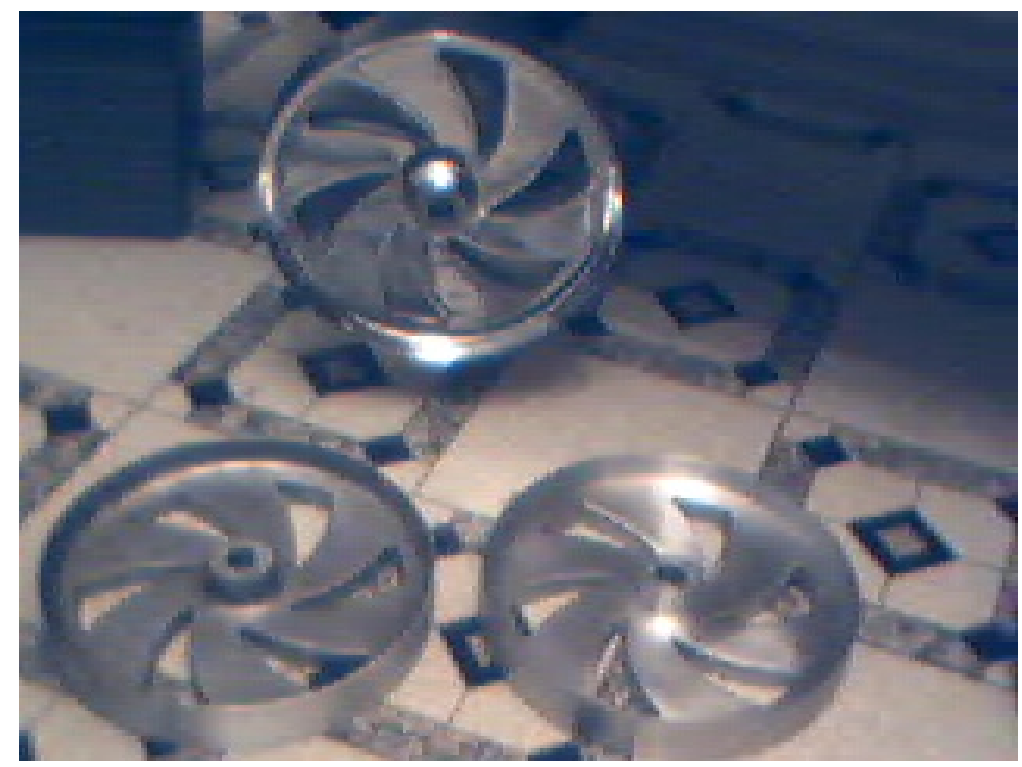

Figure 7: Finished wagon wheels
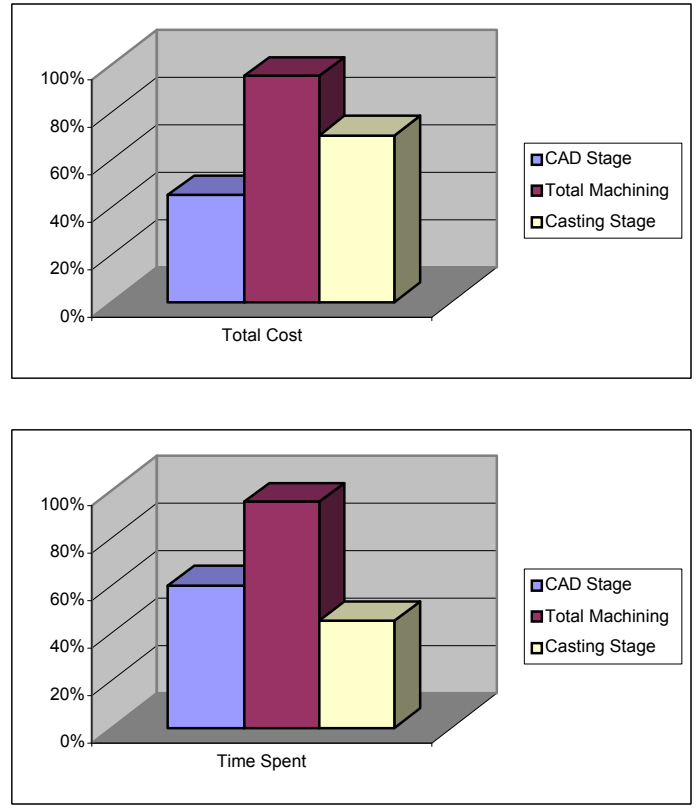

Figure 8: Sample lifecycle and cycle time estimations

\section{Instructional Support and Communication}

Starting Spring 2002 lecture notes were made available through online course management tools (WebCT was commonly used) ${ }^{8}$, and each chapter's instructor notes (in 
Microsoft Power Point) were e-mailed to the registered students via course e-mail server, mit4500-001@tntech.edu. Other than the in-class discussions and regular office visits, students used Chat and Instant Messenger to communicate the team members, and instructors. Many web companions were also used during the Fall 2002 semester: i.e: material selection, tool selection, process parameters selection ${ }^{9}$.

\section{Evaluation and Assessment}

Since this course was a new development, students' assessments were an important factor to measure the success of the course. The feedback received from the students proved that such an integrated design and manufacturing course was a great plus for any graduating senior student. Students clearly mentioned that they improved their past practices, computer skills, presentation and writing skills. Then, starting Fall 2002 this new development became one of the elective senior courses in the department ${ }^{2}$.

\section{Conclusion}

As a result, implementation of this senior level integrated design and manufacturing course was a great success. Students had a chance to practice their past learnings e.g. $\mathrm{CAD}, \mathrm{CAM}, \mathrm{CNC}$ and Casting via this new course right before their job hunting. The graduating students made many constructive remarks, and this course was made an elective course for the Tennessee Tech IT majors after Fall2001 beta testing stage.

\section{Acknowledgements}

Special thanks are conveyed to Fall 2001 and Fall 2002 graduating seniors and Barry Allison, Engineering Lab Technician.

\section{Bibliographic Information}

1. http://www.tntech.edu/it/industrial_technology_course_des.htm

2. http://www2.tntech.edu/ugcat/2002/mit.htm

3. http://www.tntech.edu/it/Curriculum\%20Spring\%202003.htm

4. C. Donaldson, G. H. LeCain, and V. C. Goold, Tool Design, $3^{\text {rd }}$ Edition, McGraw-Hill, 1999. 
5. J. G. Nee, Fundamentals of Tool Design, SME, $4^{\text {th }}$ Edition, 1998.

6. F. Nanfara, T. Uccello, and D. Murphy, The CNC Workshop-A MultiMedia Introduction to Computer Numerical Control, Version 2, Schroff Development Corporation, 2002.

7. R. Cozzens, Mastercam Workbook, Schroff Development Corporation, 2002.

8. http://webct.tntech.edu/SCRIPT/MIT450000102F/scripts/serve_home

9. http://www.tntech.edu/sme/webbook.htm

\section{Biographical Information}

\section{ISMAIL FIDAN}

Dr. Ismail Fidan is a faculty member at the MIT department of Tennessee Tech University, Cookeville, TN. He began his academic appointment in August 2000. Dr. Fidan received his PhD in Mechanical Engineering from Rensselaer Polytechnic Institute in 1996. He is a senior member of IEEE and SME, and member of ASEE, NAIT, ASME, TAS and SMTA. Dr. Fidan also serves as an associate editor for the IEEE Transactions on Electronics Packaging Manufacturing and editorial board member for the NAIT Journal of Industrial Technology and SAE Journal of Manufacturing and Materials. Dr. Fidan is the recipient of 2003 Tennessee Tech University Exemplary Course Project Award, 2003 SME Outstanding Young Manufacturing Engineer Award, 2002 Provost 'Utilization of Technology in Instruction' Award, 2002 Technology Award by The Institute for Technological Scholarship, 2001 NAIT Outstanding Professor Award. His teaching and research interests are computer integrated design and manufacturing, electronics manufacturing, and manufacturing processes.

\section{ALI SEKMEN}

Dr. Ali Sekmen is an Assistant Professor of Computer Science at Tennessee State University. He received his Ph.D. degree in Electrical Engineering from Vanderbilt University, Nashville, Tennessee. He holds B.S. and M.S. degrees in Electrical and Electronics Engineering from Bilkent University, Ankara, Turkey. He has published over 40 research papers in robotics, intelligent systems, and signal processing. He was a member of Intelligent Robotics Laboratory of Vanderbilt University between 1997-2000. Previously, he was an Assistant Professor of Electrical and Computer Engineering at Tennessee State University. He has been involved in research projects including human-robot interaction, intelligent systems, mobile robots, humanoid robots, and component-based software systems development. Dr. Sekmen is a member of the Institute of Electrical and Electronic Engineers (IEEE).

\section{FRED VONDRA}

Dr. L. Fred Vondra is an Associate Professor in the MIT department, College of Engineering, Tennessee Tech University (TTU), Cookeville, TN. He has been at TTU since 1997. Dr. Vondra received his 
Doctorate in Industrial Technology at the University of Northern Iowa in 1992. He is a member of AFS and serves on the AFS Division 7 Pattern and Foundry Tooling Committee. He is a member of NAIT and is the Foundry Education Foundation Key Professor at TTU. His teaching and research interests include; metal casting, maintenance technology, plant layout \& material handling, foundry process improvement, lost foam casting, sand binder evaluation and counter-gravity casting. 